\title{
Gender and Autonomy-Supportive Contexts: Theoretical Perspectives of Self-Determination and Goal Setting
}

\author{
Shinyi $\operatorname{Lin}^{1} \&$ Yu-Chuan Chen ${ }^{2}$ \\ ${ }^{1}$ Graduate Program of Business Administration, National Taichung University of Education, Taichung, Taiwan \\ ${ }^{2}$ Master Program of Higher Education Management, National Taichung University of Education, Taichung, \\ Taiwan \\ Correspondence: Shinyi Lin, Graduate Program of Business Administration, National Taichung University of \\ Education, 140 Min-Shen Road, Taichung 40306 Taiwan. Tel: 886-4-2218-3919. E-mail: slin@ntcu.edu.tw
}

Received: August 18, 2013

Accepted: September 2, $2013 \quad$ Online Published: November 12, 2013

doi:10.5539/jel.v2n4p13

URL: http://dx.doi.org/10.5539/jel.v2n4p13

\begin{abstract}
In integrating theoretical perspectives of self-determination and goal-setting, this study proposes a conceptual model with moderating and mediating effects exploring gender issue in autonomy-supportive learning in higher education as research context. In the proposed model, goal-setting attributes, i.e., individual determinants, social determinants, and situational determinants, have substantial prediction on goal attainability and goal commitment. Goal commitment has prediction on goal attainability. Additionally, perceived support mediates the causal effect of goal-setting attributes on goal attainability. In other words, goal commitment has partial mediating effect of goal-setting attributes on goal attainability. Further discussion and implications are also included in the study.
\end{abstract}

Keywords: gender, goal setting, self-determination, autonomy-supportive, goal commitment

\section{Introduction}

Gender difference has been a critical issue in understanding learning motivation and achievement. To understand the biological differences between males and females, quite a few empirical studies has been conducted in multiple domains; for example, developing computing skills of undergraduate students (Varma, 2009), acceptance toward computer based assessment (Terzis \& Economides, 2011), social anxiety of online communication (Wang, Jackson, \& Zhang, 2011), note-taking and participation in academic laptop-based activities(Kay \& Lauricella, 2011), mastery goal-setting towards learning tasks (Midgley, Kaplan, \& Middleton, 2001), and social-oriented achievement motive (Nie \& Liem, 2013). Nie and Liem (2013) conducted an empirical study with a $2 \times 2$ achievement goal measure and found that gender differences emerged in both mastery-approach and mastery-avoidance goals but not performance-related goals. Their research also showed that gender differences in learning and achievement may be due to gender differences in motivation and social expectation, and understanding gender differences in achievement motivation would lead to appropriate practices in parenting, teaching, and policy making related to gender differences.Within the organizing structure of theories of human agentic behavior, Nota, Soresi, Ferrari, and Wehmeyer (2011) posited that self-determination is a general psychological construct. They conducted an empirical study covering the factors of self-determination, quality of life, self-efficacy, and assertiveness with a series of multivariate analyses of variance to over a thousand Italian adolescents. To examine self-determination by gender, Nota et al. (2011) reported that the males scored positive as compared to the females in each of the domains; that is, self-determination toward expressing and making use of abilities and decisions, self-determination toward leisure time, and self-determination toward expressing ideas and feelings. In addition, females with higher levels of self-determination tend to reveal higher levels of satisfaction with help availability.

Rooted in goal setting theory, Levy and Baumgardner (1991) sought to examine the effects of self-esteem and gender on subjects' choice of goal difficulty. The predicted and confirmed the interaction effect of esteem and gender on goal choice; that is, high esteem individuals and male participants tend to choose more difficult goals than do low esteem individuals and female participants. Associated with biological differences of the genders, individual difference variables such as self-esteem, need for achievement, and locus of control were also included in the study. Specifically, their findings suggested that this gender difference existed in perception of 
success spills over into goal choice: more confident males who perceive successes are more likely to choose difficult, or say challenging goals. On the other hand, less confident females who perceive successes as due largely to luck may choose easier goals, because those goals tend to be safe and readily attainable. Despite the predictions have been empirically validated that performance in the workplace are important antecedents in determining goal choice, Levy and Baumgardner (1991) called for further research in this domain. Along the line, Midgley et al. (2001) agreed upon that some researchers have called for a reconceptualization of goal theory that acknowledges the positive effects or performance-approach goals, and the gendering effect. They concluded that males are more facilitative in performing goals in competitive learning environments. Nonetheless, the suggested reconceptualization of goal theory is not warranted (Midgley et al., 2001). As elaborated, the goal of the study is to further our understanding of the gender effect in autonomy-supportive learning contexts in higher education from the perspective of self-determination and goal setting.

\section{Development of Conceptual Model and Propositions}

To gain a better understanding on the aforementioned issues, this study proposes a conceptual model with integrating theoretical perspectives of self-determination and goal-setting. This study brings out a conceptual moderating and mediating model exploring gender issue in autonomy-supportive learning in higher education as research context. The theoretical framework is illustrated in Figure 1, and the four propositions are stated accordingly.

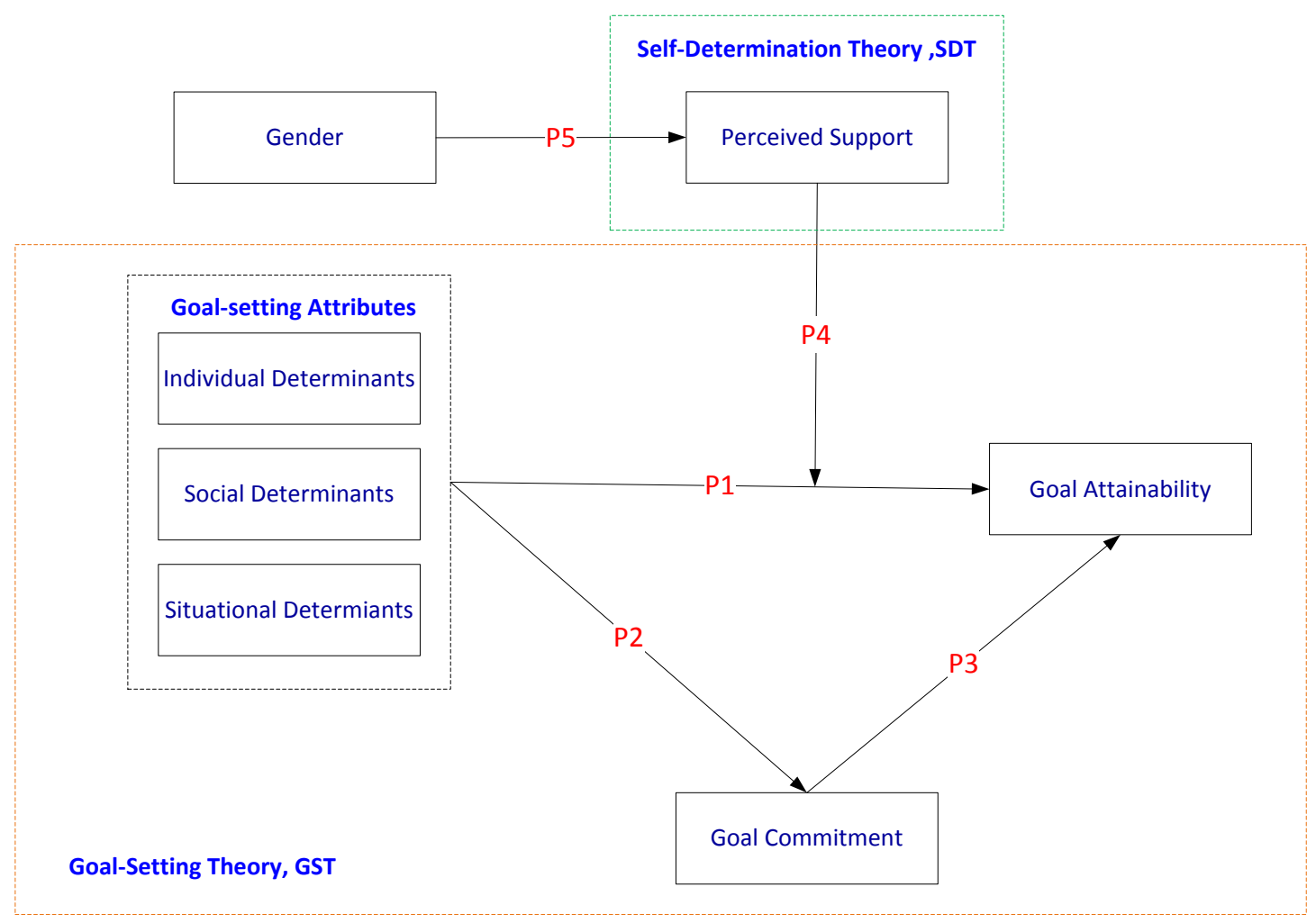

Figure 1. Conceptual model of GST and SDT

\section{P1: Goal-setting attributes have prediction on goal attainability}

P2: Goal-setting attributes have prediction on goal commitment

\section{P3: Goal commitment has prediction on goal attainability}

P4: Perceived support mediates the causal effect of goal-setting attributes on goal attainability

P5: Gender differs in perceived support in autonomy-supportive contexts

\subsection{Goal-Setting Theory (GST)}

Originated from Locke, Cartledge, and Knerr (1970), goal-setting theory (GST) has been applied afterwards to understand many fields of interest . Goal-setting theory states that for goals to be motivational, they must not only be specific and challenging but also achievable or attainable. Once again, the relative importance of goal 
achievability to employee motivation and efforts may be mitigated by time. Employees may be encouraged to adopt or commit to risky goals with lower likelihood of achieving them if the valence associated with achieving these goals is high and if the failure to achieve them is considered by the focal individuals and their organizations to be temporary and potentially correctable in future time.

(Fried \& Slowik, 2004). For instance, Miles and Clenney (2012) applied goal-setting theory to test negotiation outcomes; that is, they intend to understand whether goals set substantially beyond challenging yet attainable result in either plateaued or decreased objective negotiation outcomes. Another example of Fang, Evans, and Zou (2005) is examining the moderating effects of goal-setting characteristics between sales control systems and job performance among sales managers. Their research findings suggest the need to take into account of goal-setting characteristics when one attempts to associate sales control systems with salesperson's job performance. In their study of enriching goal-setting theory with time, Fried and Slowik (2004) asserted that more challenging goals cause people to work longer on a task. Locke and Latham (1990) identified the three factors, goal difficulty, goal specificity, and goal participation, as basic characteristics of goal-setting theory. Accordingly, goal difficulty refers to the degree to which the goals assigned by a supervisor are attainable, whereas goal specificity is defined as the extent to which the goals are clearly defined by a supervisor, and goal participation is the degree of involvement of salespeople in setting the goals. Poujol, Fournier, and Tanner Jr (2011) posited that goal acceptance is also independently predictive of effort and performance, but the combination of perceived contest difficulty and acceptance yields the highest levels of effort and performance. In addition, be sure to raise the level of specific goals and secure the commitment to the goals in order to increase performance. One of the major tenets of the theory argues that one's expectancy of performing a certain behavior will lead to a particular outcome, and this expectancy influences his or her attitude and intent in performing that behavior (Miles \& Clenney, 2012). Shih (1998) presented in this paper shows that the attainability of the consolidated goal often differs dramatically from that of the subunit goals. If the subunit goals are all difficult (easy) to attain, it is almost always the case that the consolidated goal is even harder (easier) to attain. The analysis also reveals that the correlation of the performances of the subunits impacts the attainability of the consolidated goal in a predictable fashion. In particular, the higher the correlation of the subunit performances the more the attainability of the consolidated goal approaches the attainability of the subunit goals. These results of the paper have implications for settings in which consolidated performance goals are derived from a simple aggregation of subunit goals.

\section{P1: Goal-setting attributes have prediction on goal attainability}

Most goal-setting studies have focused on the effects of assigned goals (Locke, Latham, \& Erez, 1988). As a key aspect of goal-setting theory, the strength of the relationship between commitment and performance is asserted to depend on the amount of variance in commitment (Locke et al., 1988). Three major categories of determinants of commitment are discussed: external factors (authority, peer influence, external rewards), interactive factors (participation and competition), and internal factors (expectancy, internal rewards). Locke, Shaw, Saari, and Latham (1981) posited that different degrees of goal commitment might be influenced by fluctuating degrees of social influence (e.g., approval, disapproval). And such influences unquestionably have profound effects on goal choice and commitment among certain individuals. In the study of Sholihin, Pike, Mangena, and Li (2011), they investigated whether goal-setting participation affects goal commitment, and whether the effect is mediated by procedural fairness and interpersonal trust. From 54 managers of a UK major financial services organization, Sholihin et al. (2011) found that goal-setting participation is positively associated with goal commitment, and suggested that both procedural fairness and trust play an important role on the association between goal-setting participation and goal commitment. In understanding compensation plans with incentive values, Liccione (2007) defined goal commitment as individuals' commitment to their goals and consequent interest in pursuing them. Ultimately, goal commitment is only maximized if employees are held most accountable for the goals over which they have the most control(Liccione, 2009). Liccione (2007) posited that when individuals define their goals to be consistent with their personal aspirations, the resulting commitment to goal attainment signifies a driving motivational force.

\section{P2: Goal-setting attributes have prediction on goal commitment}

\section{P3: Goal commitment has prediction on goal attainability}

\subsection{Self-Determination Theory (SDT)}

Proposed by E. L. Deci and Ryan (1985), self-determination theory (SDT) has been applied in the context of ICT-integrated learning. SDT has the potential to address learning issues such as student attrition in the online learning environment (Chen \& Jang, 2010), high school students' Internet use (Zhao, Lu, Wang, \& Huang, 2011), 
scaffolding and motivation in CSCL (Rienties et al., 2012), e-learning continuance intention in the workplace (Roca \& Gagné, 2008), teachers' motivation to continue to use e-learning technology (Sørebø, Halvari, Gulli, \& Kristiansen, 2009). E. L. Deci and Ryan (1985) identified two general types of motivation. Ryan and Deci (2000) defined intrinsic motivation as the doing of an activity for its inherent satisfactions rather than for some separable consequence (p. 56). For the operational definition, Ryan and Deci (2000) brought up with two measures that have been most often used: (1) the conduct of experimental research; (2) the use of self-reports of interest and enjoyment of the activity per se. Drawing on Deci and Ryan's self-determination theory, Chen and Jang (2010) proposed a model for online learner motivation in two online certificate programs, and found the support that intrinsic motivation, extrinsic motivation, and amotivation are distinctive constructs.

Derived from the performance, intrinsically motivated behaviors are engaged in for their own sake for the pleasure and satisfaction(E. L. Deci, Vallerand, Pelletier, \& Ryan, 1991). When intrinsically motivated, students would engage in activities that interest them, and they do so freely, with a full sense of volition and without the necessity of material rewards or constraints (E. L. Deci \& Ryan, 1985). Extrinsically motivated behaviors, on the other hand, are instrumental in nature. They are performed not out of interest but because they are believed to be instrumental to some separable consequence (E. L. Deci et al., 1991). That is, SDT is a framework of motivation that considers humans to be actively searching optimal challenges and new experiences to master and integrate (E. L. Deci et al., 1991). E. L. Deci et al. (1991) believe that promoting students' self-determined motivation should be the highest priority of educational endeavors.

According to SDT, supports for competence (e.g., optimal challenges and performance feedback) and for relatedness (e.g., parental involvement and peer acceptance) facilitate motivation (E. L. Deci et al., 1991). Through an online survey conducted from January to April 2006 among an international umbrella organization of 15 national academies of management, Moosmayer (2012) developed and tested a model to explain management academics' intention to influence values according to their individual and social determinants. Of 1254 participants, Moosmayer (2012) found that perceived support is the strongest predictor of academics' intentions to influence values. Moosmayer (2012) also concluded that academic institutions might increase academics' intentions by supporting value influences, but they also need to leave sufficient space for informal influences. First, academics must bring their own social values into the classroom, and second, students need role models that display consideration of others and space for individual thoughts and behaviors in the context of the academic institution (Moosmayer, 2012). In line with the applicability of self-determination theory, Roca and Gagné (2008) studied the continuance intention of e-learning service in the workplace, and concluded that an autonomy-supportive context could lead to enhance users' extrinsic and intrinsic motivation and further to achieve their instrumental goals.

P4: Perceived support mediates the causal effect of goal-setting attributes on goal attainability

\section{P5: Gender differs in perceived support in autonomy-supportive contexts}

\section{Discussion and Future Research}

This study intends to provide the theoretical framework of autonomous-supportive contexts in which gender perceives differently in self-determination and goal-setting attributes. The process and content of goal pursuits make a difference for performance and well-being, the evidence does indicate that the process and content of goal pursuits make a difference to the quality of life, and it is the relation of motivated behavior to satisfaction of the basic needs for autonomy, competence, and relatedness that allows a meaningful integration of these findings (Edward L. Deci \& Ryan, 2000). Amorose and Anderson-Butcher (2007) applied self-determination theory as a theoretical framework to test whether perceived competence, autonomy, and relatedness mediated the relationship between perceived autonomy-supportive coaching and motivational orientation among 581 high school and college athletes. Their results revealed that the sample athletes perceived their coaches to be autonomy-supportive significantly predicted the athletes' perceived competence, autonomy, and sense of relatedness, which, in turn, each predicted their motivational orientation. The relationship between enduring or personality characteristics and goal choice has been of considerable theoretical, but little empirical interest in recent years (Levy \& Baumgardner, 1991). From a practical perspective, Sholihin et al. (2011) concluded that in the design of performance evaluation systems, goal commitment is enhanced when subordinates are encouraged to participate in setting goals, performance evaluation procedures are perceived as fair and the level of interpersonal trust is high. Dietrich and Salmela-Aro (2013) investigated Finnish adolescents' and parents' co-regulation of career-related goals during the post-school transition. How their career goal motivation (autonomous vs. controlled) and appraisals (goal attainability, effort, progress, and stress) interact with their perceptions of parents' career-related involvement (support and lack of engagement) was assessed during the 
transition. Dietrich and Salmela-Aro (2013) found that both perceived career-specific parental involvement and warmth were associated, albeit weakly, with goal-related stress three years later. This link was mediated by controlled career goal motivation. Along the line, goal commitment represents a source of motivation for goal pursuit that is separate from and that precedes individuals' assessments of goal attainability or the value of the rewards they are likely to receive for attaining the goals (Liccione, 2007). The preliminary finding of this study has not only of theoretical importance but also have important practical implications for the intended interest. In the follow-up, the result lends support to a large-scale empirical study.

\section{Reference}

Amorose, A. J., \& Anderson-Butcher, D. (2007). Autonomy-supportive coaching and self-determined motivation in high school and college athletes: A test of self-determination theory. Psychology of Sport and Exercise, 8(5), 654-670. http://dx.doi.org/10.1016/j.psychsport.2006.11.003

Chen, K. C., \& Jang, S. J. (2010). Motivation in online learning: Testing a model of self-determination theory. Computers in Human Behavior, 26(4), 741-752. http://dx.doi.org/10.1016/j.chb.2010.01.011

Deci, E. L., \& Ryan, R. M. (1985). Intrinsic motivation and self-determination in human behavior. New York: Plenum. http://dx.doi.org/10.1007/978-1-4899-2271-7

Deci, E. L., \& Ryan, R. M. (2000). The "What" and "Why" of Goal Pursuits: Human Needs and the Self-Determination of Behavior. Psychological Inquiry, 11(4), 227-268. http://dx.doi.org/10.1207/S15327965PLI1104_01

Deci, E. L., Vallerand, R. J., Pelletier, L. G., \& Ryan, R. M. (1991). Motivation and education: The self-determination perspective. Educational Psychologist, 26(3-4), 325-346. http://dx.doi.org/10.1080/00461520.1991.9653137

Dietrich, J., \& Salmela-Aro, K. (2013). Parental involvement and adolescents' career goal pursuit during the post-school transition. Journal of Adolescence, 36(1), 121-128. http://dx.doi.org/10.1016/j.adolescence.2012.10.009

Fang, E., Evans, K. R., \& Zou, S. (2005). The moderating effect of goal-setting characteristics on the sales control systems-job performance relationship. Journal of Business Research, 58(9), 1214-1222. http://dx.doi.org/10.1016/j.jbusres.2004.03.006

Fried, Y., \& Slowik, L. H. (2004). Enriching goal-setting theory with time: An integrated approach. Academy of Management Review, 29(3), 404-422.

Kay, R. H., \& Lauricella, S. (2011). Gender Differences in the Use of Laptops in Higher Education: A Formative Analysis. Journal of Educational Computing Research, 44(3), 361-380. http://dx.doi.org/10.2190/EC.44.3.f

Levy, P. E., \& Baumgardner, A. H. (1991). Effects of self-esteem and gender on goal choice. Journal of Organizational Behavior, 12(6), 529-541. http://dx.doi.org/10.1002/job.4030120606

Liccione, W. J. (2007). A FRAMEWORK FOR COMPENSATION PLANS WITH INCENTIVE VALUE. Performance Improvement, 46(2), 16-21. http://dx.doi.org/10.1002/pfi.103

Liccione, W. J. (2009). Goal commitment. Performance Improvement, 48(7), 26-30. http://dx.doi.org/10.1002/pfi.20092

Locke, E. A., Cartledge, N., \& Knerr, C. S. (1970). Studies of the relationship between satisfaction, goal-setting, and performance. Organizational Behavior and Human Performance, 5(2), 135-158. http://dx.doi.org/10.1016/0030-5073(70)90011-5

Locke, E. A., \& Latham, G. P. (1990). Work Motivation and Satisfaction: Light at the End of the Tunnel. Psychological Science, 1(4), 240-246. http://dx.doi.org/10.1111/j.1467-9280.1990.tb00207.x

Locke, E. A., Latham, G. P., \& Erez, M. (1988). The Determinants of Goal Commitment. The Academy of Management Review, 13(1), 23-39.

Locke, E. A., Shaw, K. N., Saari, L. M., \& Latham, G. P. (1981). Goal setting and task performance: 1969-1980. Psychological Bulletin, 90(1), 125-152. http://dx.doi.org/10.1037/0033-2909.90.1.125

Midgley, C., Kaplan, A., \& Middleton, M. (2001). Performance-approach goals: Good for what, for whom, under what circumstances, and at what cost? Journal of Educational Psychology, 93(1), 77-86. http://dx.doi.org/10.1037/0022-0663.93.1.77 
Miles, E. W., \& Clenney, E. F. (2012). Extremely difficult negotiator goals: Do they follow the predictions of goal-setting theory? Organizational Behavior and Human Decision Processes, 118(2), 108-115. http://dx.doi.org/10.1016/j.obhdp.2012.02.001

Moosmayer, D. C. (2012). A Model of Management Academics' Intentions to Influence Values. [Article]. Academy of Management Learning \& Education, 11(2), 155-173. http://dx.doi.org/10.5465/amle.2010.0053

Nie, Y., \& Liem, G. A. D. (2013). Extending antecedents of achievement goals: The double-edged sword effect of social-oriented achievement motive and gender differences. Learning and Individual Differences, 23(0), 249-255. http://dx.doi.org/10.1016/j.lindif.2012.10.006

Nota, L., Soresi, S., Ferrari, L., \& Wehmeyer, M. (2011). A Multivariate Analysis of the Self-Determination of Adolescents. Journal of Happiness Studies, 12(2), 245-266. http://dx.doi.org/10.1007/s10902-010-9191-0

Poujol, F. J., Fournier, C., \& Tanner Jr, J. F. (2011). Compliance versus preference: Understanding salesperson response to contests. Journal of Business Research, 64(7), 664-671. http://dx.doi.org/10.1016/j.jbusres.2010.08.016

Rienties, B., Giesbers, B., Tempelaar, D., Lygo-Baker, S., Segers, M., \& Gijselaers, W. (2012). The role of scaffolding and motivation in CSCL. Computers \& Education, 59(3), 893-906. http://dx.doi.org/10.1016/j.compedu.2012.04.010

Roca, J. C., \& Gagné, M. (2008). Understanding e-learning continuance intention in the workplace: A self-determination theory perspective. Computers in Human Behavior, 24(4), 1585-1604. http://dx.doi.org/10.1016/j.chb.2007.06.001

Ryan, R. M., \& Deci, E. L. (2000). Self-determination theory and the facilitation of intrinsic motivation, social $\begin{array}{lllll}\text { development, } \quad \text { and } & \text { well-being. }\end{array}$ http://dx.doi.org/10.1037/0003-066X.55.1.68

Sørebø, Ø., Halvari, H., Gulli, V. F., \& Kristiansen, R. (2009). The role of self-determination theory in explaining teachers' motivation to continue to use e-learning technology. Computers \& Education, 53(4), 1177-1187. http://dx.doi.org/10.1016/j.compedu.2009.06.001

Shih, M. S. H. (1998). Corporate hierarchy and goal attainability. [Article]. Accounting Review, 73(4), 557.

Sholihin, M., Pike, R., Mangena, M., \& Li, J. (2011). Goal-setting participation and goal commitment: Examining the mediating roles of procedural fairness and interpersonal trust in a UK financial services organisation. The British Accounting Review, 43(2), 135-146. http://dx.doi.org/10.1016/j.bar.2011.02.003

Terzis, V., \& Economides, A. A. (2011). Computer based assessment: Gender differences in perceptions and acceptance. Computers in Human Behavior, In Press, Corrected Proof. http://dx.doi.org/10.1016/j.chb.2011.06.005

Varma, R. (2009). Gender differences in factors influencing students towards computing. Computer Science Education, 19(1), 13. http://dx.doi.org/10.1080/08993400902819006

Wang, J. L., Jackson, L. A., \& Zhang, D. J. (2011). The mediator role of self-disclosure and moderator roles of gender and social anxiety in the relationship between Chinese adolescents' online communication and their real-world social relationships. Computers in Human Behavior, In Press, Corrected Proof. http://dx.doi.org/10.1016/j.chb.2011.06.010

Zhao, L., Lu, Y., Wang, B., \& Huang, W. (2011). What makes them happy and curious online? An empirical study on high school students' Internet use from a self-determination theory perspective. Computers \& Education, 56(2), 346-356. http://dx.doi.org/10.1016/j.compedu.2010.08.006

\section{Copyrights}

Copyright for this article is retained by the author(s), with first publication rights granted to the journal.

This is an open-access article distributed under the terms and conditions of the Creative Commons Attribution license (http://creativecommons.org/licenses/by/3.0/). 